\title{
マルチガスセンサとプロダクションシステムを用いた 室内空気污染ガスの検知システム
}

\author{
広 林 茂 樹*·木 村 春 彦*・南 保 英 孝* \\ 坂 森 智*.大 薮 多可志**
}

\begin{abstract}
Detection of Gaseous Indoor-Air Pollutants Using Multi Gas Sensor System and a Production System
\end{abstract}

Shigeki HirobaYASHI*, Haruhiko Kimura*, Hidetaka NAmbo*, Satoshi SAKAMORI* and Takashi OYABU**

\begin{abstract}
By observing each output signal from experiments to recognize each of 6 gas sensors to measure the degree of indoor environmental pollution quantitatively, 7 kinds of simple gas, and one kind of complex gas were attempted. An independent recognition rule was established for each gas ( 8 rules). The result was determined from the position of a 6 -dimension vector comprised of 6 sensor responses within the range determined by each rule, and a simple concentration index of the target gas was calculated from the input signal. As a result, 8 ranges were determined for each rule in 6-dimension vector spaces appeared to exist independently for the most part. However, negligible mistake in determination was confirmed in a low density area close to regular output in the determination experiment, information that can supplement the determination using a density guideline value should be obtained. The recognition rate without concentration correction was $99 \%$. With concentration correction, $100 \%$ recognition rate could be obtained.
\end{abstract}

Key Words: gas sensor, indoor-air pollutants, OPS5, production system

\section{1.はじめに}

社会環境の変遷とともに住環境が大きく変化している. 特 に, 熱, 空気, 音, 光などの室内環境の中で空気環境の悪化 が大きな問題となっている ${ }^{1)}$ 。これまで，室内空気污染はビ ル管理法などにより，二酸化炭素ガスの濃度が指標となって いる。しかし，室内におけるエネルギー消費の変遷とともに さまざまな空気污染源が存在するようになってきた，特に， 可燃性ガスや灯油などの燃焼による窒素酸化物，タバコ，一 酸化炭素ガスなどによる污染が増加する傾向にある。また， 住宅建材から発生するホルムアルデヒドなどによりシックビ 儿症侯群が多発し，人体に害を与えることから大きな社会問 題となってきている。しかしながら，ガスセンサは選択性に そしく，対象とする污染ガスだけに反応するセンサは現在ま でのところ,どのガスに対してもまだない。このため，污染

* 金沢大学工学部 金沢市小立野 2-40-20

** 金沢経済大学経済学部 金沢市御所町丑 10 番地

* Faculty of Engineering, Kanazawa University, Kanazawa

** Kanazawa College of Economics, Kanazawa

(Received November 13, 1997)

(Revised April 6, 1998)
ガス種の検知や危険なガスの濃度を測定することが必要不可 欠となってきている。

本論文では，マルチガスセンサ（絶対湿度検知センサ，ア ンモニアセンサ, 可燃性ガスセンサ, 一酸化炭素センサ, 二酸 化炭素センサ, 窒素酸化物センサ) とプロダクションシステ ムを用いて，家庭内で発生する污染ガス（メタン，エタノー ル, プロパン, 一酸化炭素, 二酸化炭素, ホルムアルデヒド, アンモニア，タバコの煙）の種類を検知するシステムを提案 する，また，本システムは単一ガスの検知として，ガス種と その濃度指標の算出を行うものである。 また複合ガスとして タバコの煙を判定し, 複合ガス検知の可能性を調べる.

本論文と類似した研究には以下のものがある。まず，4種 類のセンサ（可燃性ガスセンサ, 一酸化炭素センサ, 温度計, 湿度計）からの出力特性を入力し，家庭内で発生する 3 つの 災害 (火災，ガス漏れ，一酸化炭素ガスの発生）を検知する プロダクションシスこム2)や，この 4 種類のセンサからの出 力特性の代りに微分特性を扱うことにより検知時間を短縮し た改善案 ${ }^{3)}$, 酸化スズ系ガスセンサのみを用いて日常時の室 内空気污染度を推論し, 測定した空気污染度と相対比較がで きるようにしたシステム4) 6)などがある。

以下に，2．で検知システムを紹介し，3．で污染ガスの種 
類を検知する方法を示す。ここでは, 検知ルールの合理性, ルールによる判定の正確さ, 知識ベースとの対応関係につい て述べる．4. では濃度測定の方法について説明し，5. で実 験により本システムの有効性を示す．6. はまとめである．な お，付録に実際に用いた知識ベースとその解説を載せた.

\section{2. 検知システム}

提案する検知システムは 6 種類のセンサを備えたマルチセ ンサとプロダクションシステムから構成されている.

マルチセンサの各センサは熱環境測定のための絶対湿度を 検知するセンサ (AHS)，アンモニアセンサ (AMS)，可燃 性ガスセンサ (CGS)，一酸化炭素センサ (COS)，二酸化 炭素センサ $(\mathrm{CO} 2 \mathrm{~S})$, 窒素酸化物センサ $(\mathrm{NXS})$ である。こ れらのセンサは対象とするガスだけに反応するものではなく， 他の何種類かのガスにも反応するため, 選択性に欠けること が知られている. 用いたマルチセンサについての詳細は文献 7）を参照されたい.

プロダクションシステムはエキスパートシステム構築用 ツールである．エキスパートシステムは専門家の代行を務め るシステムである. プロダクションシステムは, プロダクショ ンメモリ，ワーキングメモリ，推論エンジンから構成される。 プロダクションメモリにはルールの集合である知識ベースが 入り，ワーキングメモリにはデータであるワーキングメモリ エレメント (WME) が格納される. 推論エンジンはプロダ クションメモリからワーキングメモリ内の WME によって 条件を満足するルールをすべて探し出し，その中から競合解 決戦略によって 1 つのルールを選び出し，それを実行させる 認知一動作サイクルを繰り返すプログラムである．用いたプ ロダクションシステムは OPS5 である．詳細については文献 8）を参照されたい.

提案システムでは, マルチセンサとコンピュータ（パソコ ン）を接続し、コンピュータ内のプロダクションシステムの 知識ベースにより，ガス種の検知と, 簡易的な濃度測定を行 うものである.

以下にマルチセンサの出力值がプロダクションシステムに どのようにして取り达まれているかを示す。

（1）各センサは 4 秒ごとに出力值（電圧）を出し，それ らはコンピュータによりモニタされる:

（2）モニタされた同時刻の全センサの出力值から 1 つの WME が作成される.

（3）（2）で作成されたWME はルール動作部の指示に よりルール実行時にワーキングメモリに追加される。

この一連の操作によって取り込まれた WME は知識べース と条件照合され，上記のような機能を実現しているのである.

\section{3. 検知方法}

われわれはマルチセンサを用いて日常室内で発生する可能 性のあるメタン $\left(\mathrm{CH}_{4}\right)$, エタノール $\left(\mathrm{C}_{2} \mathrm{H}_{5} \mathrm{OH}\right)$, プロパ ン $\left(\mathrm{C}_{3} \mathrm{H}_{8}\right)$, 一酸化炭素 $(\mathrm{CO})$, 二酸化炭素 $\left(\mathrm{CO}_{2}\right)$, 小
ルムアルデヒド $(\mathrm{HCHO})$, アンモニア $\left(\mathrm{NH}_{3}\right)$, タバコの 煙（Cigarette Smoke）について調べた，その結果，Table 1 で示されるように，6種類のセンサを用いたマルチセンサ で，これら 8 種類のガス状空気污染物を区別することができ ることがわかった。

本提案システムの検知方法は, この Table 1 の判別知識を 知識ベース化してプロダクションシステムにより污染ガス種 を検知するものである．オフセットレベルが季節によって若 干変化 ${ }^{6)}$ するため, 本システムでは, センサ出力範囲の最大 值と最小値よりガスセンサ反応範囲を選定した.オフセット レベルとは, 污染ガスが発生していない状態でのセンサ出力 値を指し, 定常状態でのセンサ最小值に等しく, 一般的には $0 \mathrm{~V}$ ではない. 最大值とは高濃度域のセンサ収束電圧である. Fig. 1 は CGS における反応媒質 (メタン) 濃度対電圧比の 特性曲線例である。この特性図のように本システムで用いる ガスセンサはすべて反応媒質が高濃度域にあるとき，収束性 を有す．本実験では収束領域を約 $20000 \mathrm{ppm}$ に設定した，本 認知システム (付録) では, 対象としている 8 種類の污染ガ ス以外には検知できない場合や 8 種類以外の污染ガスに反応 する場合がある.これは, 知識ベースに対象としているガス 種判定アルゴリズムが無いからである．また，使用した各ガ スセンサがガスの選択性を有しておらず，各ガスセンサ応答 が独立していないことにも起因する. Fig. 2 に判定アルゴリ ズムを示す. Fig. 2 はセンサ入力から, ガス種の判定と濃度 指標の算出に至るまでの流れ図である。ガスセンサから観測 信号を測定し，入力信号が各ガス種判定ルール（計 8 ルール） のどれに一致するか検索する．測定信号 $x$ を各センサに対し

$$
x\left(V_{1}, V_{2}, \ldots, V_{6}\right)
$$

のようにベクトル化 (6 次元) し, ベクトル空間に分布させ る. $V_{1} \sim V_{6}$ は各センサから観測される入力電圧である. 次 に，与えられた知識べースによって定義されたガス種判定領 域と照らし合わせ，入力ベクトルに対し，ガス種を判定し濃 度指標を算出した。たとえば，Fig. 3 (a) における判定空間 内 (斜線部) には入力ベクトル（実線）が含まれる。しかし， Fig. 3（b）は入力ベクトルが判定空間内には収まらない.こ のとき, 本システムでは Fig. 3（a）のルールに従うガス種

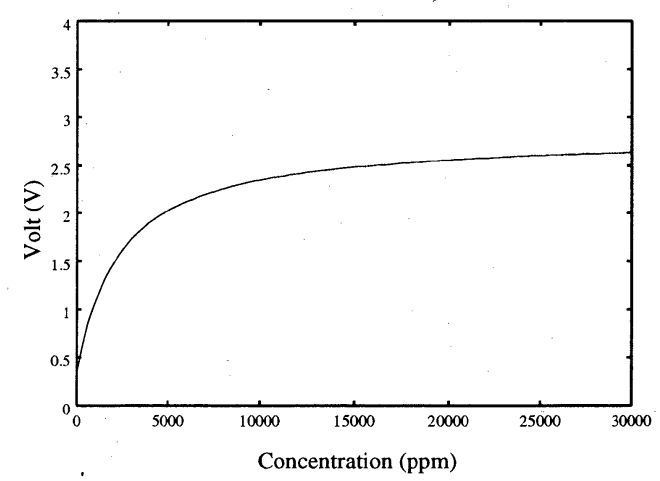

Fig. 1 The density voltage characteristic. 
Table 1 Output sensitivities of six sensors for eight gaseous indoor-air pollutants. (, $\bigcirc, \Delta$ and blank indicate vary high, high, more or less high and no response, respectively.

\begin{tabular}{|c||c|c|c|c|c|c|c|c|}
\hline & $\mathrm{CH}_{4}$ & $\mathrm{C}_{2} \mathrm{H}_{5} \mathrm{OH}$ & $\mathrm{C}_{3} \mathrm{H}_{8}$ & $\mathrm{CO}$ & $\mathrm{CO}_{2}$ & $\mathrm{HCHO}$ & $\mathrm{NH}_{3}$ & $\begin{array}{c}\text { Cigarette } \\
\text { Smoke }\end{array}$ \\
\hline \hline AHS & $\bigcirc$ & & & & & & & \\
\hline \hline AMS & & ( & & & & $\bigcirc$ & $\bigcirc$ & $\bigcirc$ \\
\hline CGS & $\bigcirc$ & $\odot$ & $\odot$ & $\bigcirc$ & & $\bigcirc$ & $\bigcirc$ & $\bigcirc$ \\
\hline COS & & $\triangle$ & & $\bigcirc$ & & & & $\bigcirc$ \\
\hline CO2S & & & & & $\bigcirc$ & & & $\bigcirc$ \\
\hline NXS & & & & & & & $\bigcirc$ & $\bigcirc$ \\
\hline
\end{tabular}
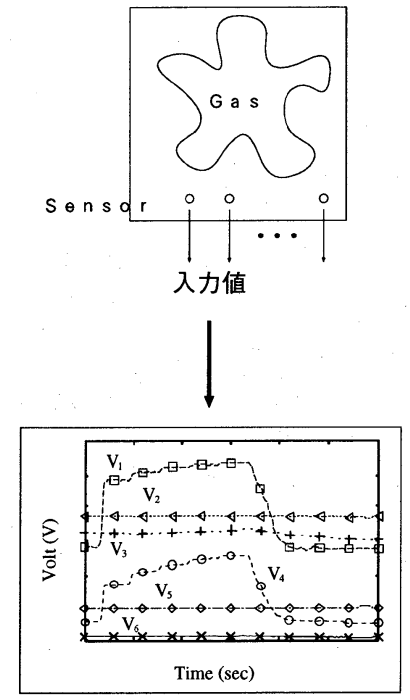

観測信号

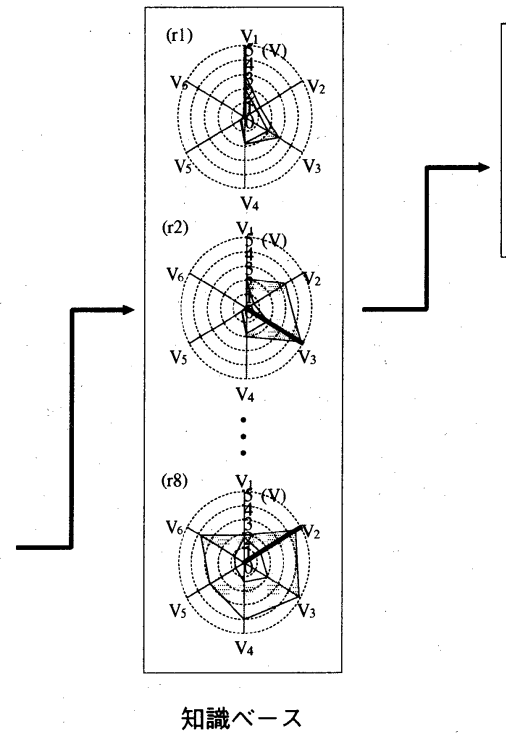

知識ベース

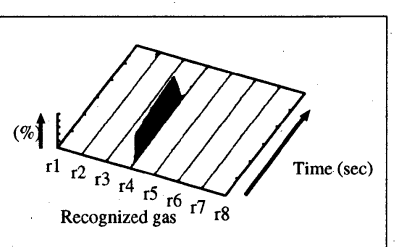

出力信号

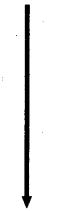

ガスの種類

ガス濃度の指標值

出力值

Fig. 2 The determination algorithm.
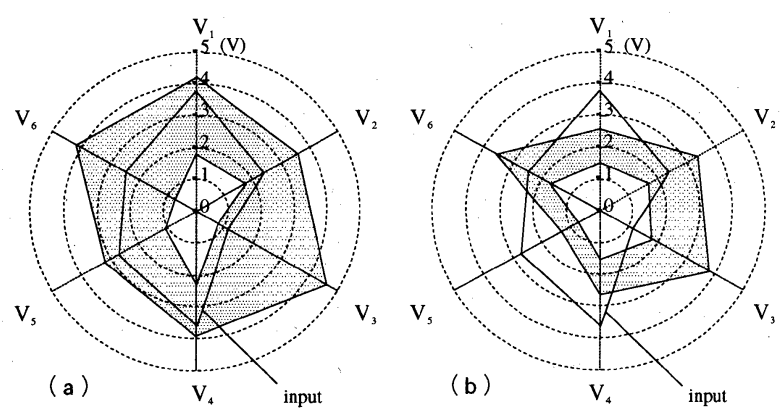

Fig. 3 Example of determination space.

を検出する，さらに，濃度指標値 $P_{c}$ を求めるため以下を用 いた.

$$
P_{c}=\frac{V_{k}-V_{k \min }}{V_{k \max }-V_{k \min }}
$$

$V_{k \max }$ と $V_{k \min }$ は各判定ルール内で最も感度が良いセンサ入 力電圧の上限と下限である。 $V_{k}$ はそのセンサに反応する入力 電圧である。したがって, 本指標では正確な濃度は検出され ないが，電圧比を用いることによって濃度に起因する概略的 な濃度指標值が算出できる．複数の特性の異なるガスセンサ で単一ガスの濃度を算出する試み ${ }^{9)}$ も行なわれているが, ガ ス濃度に対し静的な知識ベクトル情報を用いているため広濃
度域での判定が困難である。しかし，本手法ではガス濃度に 対し動的な知識ベクトル情報を用いているため, 広濃度域で の検知が可能である. Fig. 4 に知識ベースのルールの実行の 流れを示す．各ブロックの左肩に付けられているのはルール 名である，まず, startup 文により, 各センサの電圧值の範囲 を表す WME をワーキングメモリに格納する，ルール r0に よりマルチセンサの最初の測定值を取り込みワーキングメモ リに格納する。 この段階で, 各センサの出力值の上限と下限 に基づいて, 対象とする污染ガスの発生状態に対して条件照 合を行い, 条件が一致するものがあれば検出した污染ガス名 とそのときの濃度指標值がディスプレイに表示される. 複数 の污染ガスが検出された場合は, 検出されたすべての污染ガ スについて表示する。 つまり, 該当するルールは $\mathrm{r} 1, \mathrm{r} 2, \cdots$, $\mathrm{r} 8$ は並列に実行される，この後，ルール r10によりつぎの測 定值が取り込まれる. 測定值が污染ガスの条件のいずれにも 一致しなかった場合には，ルール r9 によりつぎの測定値が 取り込まれ，污染ガスの条件照合が続行される.

ルール r1，r2，，r8 は対象としている污染ガスを検知す るルールである.これらは Fig.5 のガス種判定領域をルー ル化したものである．測定值がルールの条件を満足すれば, ルールに対応する污染ガス種を検知し, 濃度指標値を算出す 


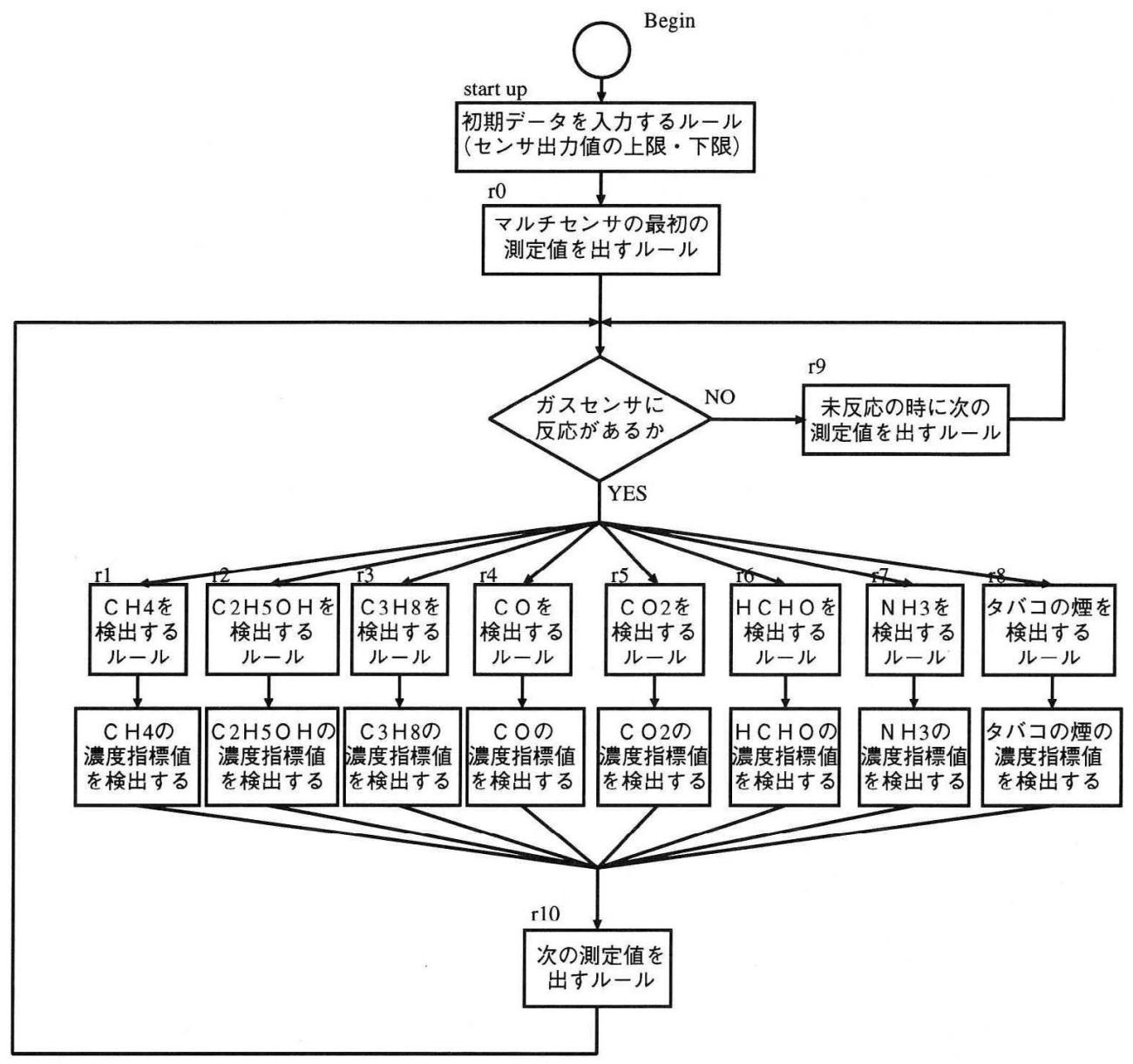

Fig. 4 The flow of the rule of knowledge base.

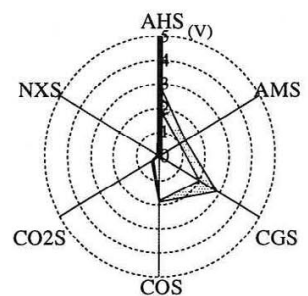

(a) $\mathrm{CH} 4$

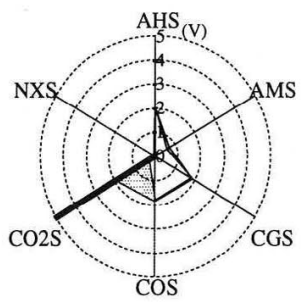

(ө) $\mathrm{CO}_{2}$

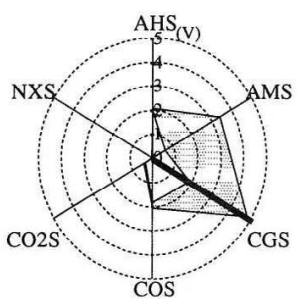

(b) $\mathrm{C} 2 \mathrm{H} 5 \mathrm{OH}$

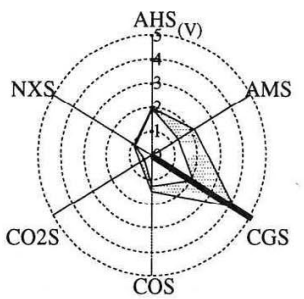

(f) $\mathrm{HCHO}$

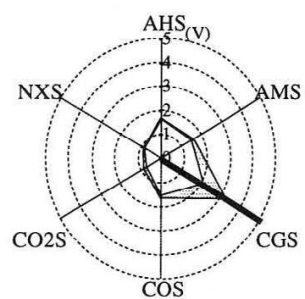

(c) $\mathrm{C} 3 \mathrm{H} 8$

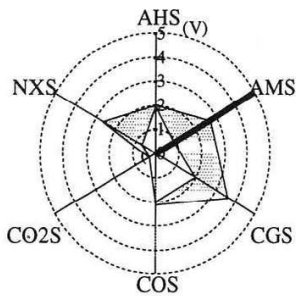

(g) $\mathrm{NH}_{3}$

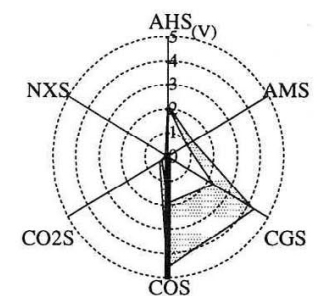

(d) $\mathrm{CO}$

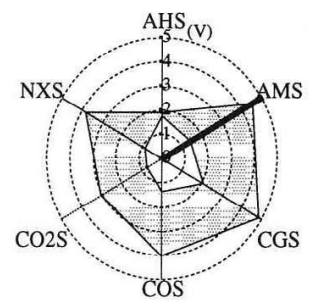

(h) $\operatorname{cigar\theta tat} \theta$

Fig. 5 The rule of a knowledge vector area.

る、ルール r9 は，ガスが検出されなかったときにつぎの測 定值を取り込むルールである。ルール r10 は，ガス検出の後 につぎの測定値を取り込むルールである，以上のようにして， マルチセンサの測定値が入力されるたびに，条件照合を行い，
污染ガスの検知が行われる。

\section{4. 濃 度 測 定}

実験では 200 リットルの容器に 8 種類のガスをそれぞれ 

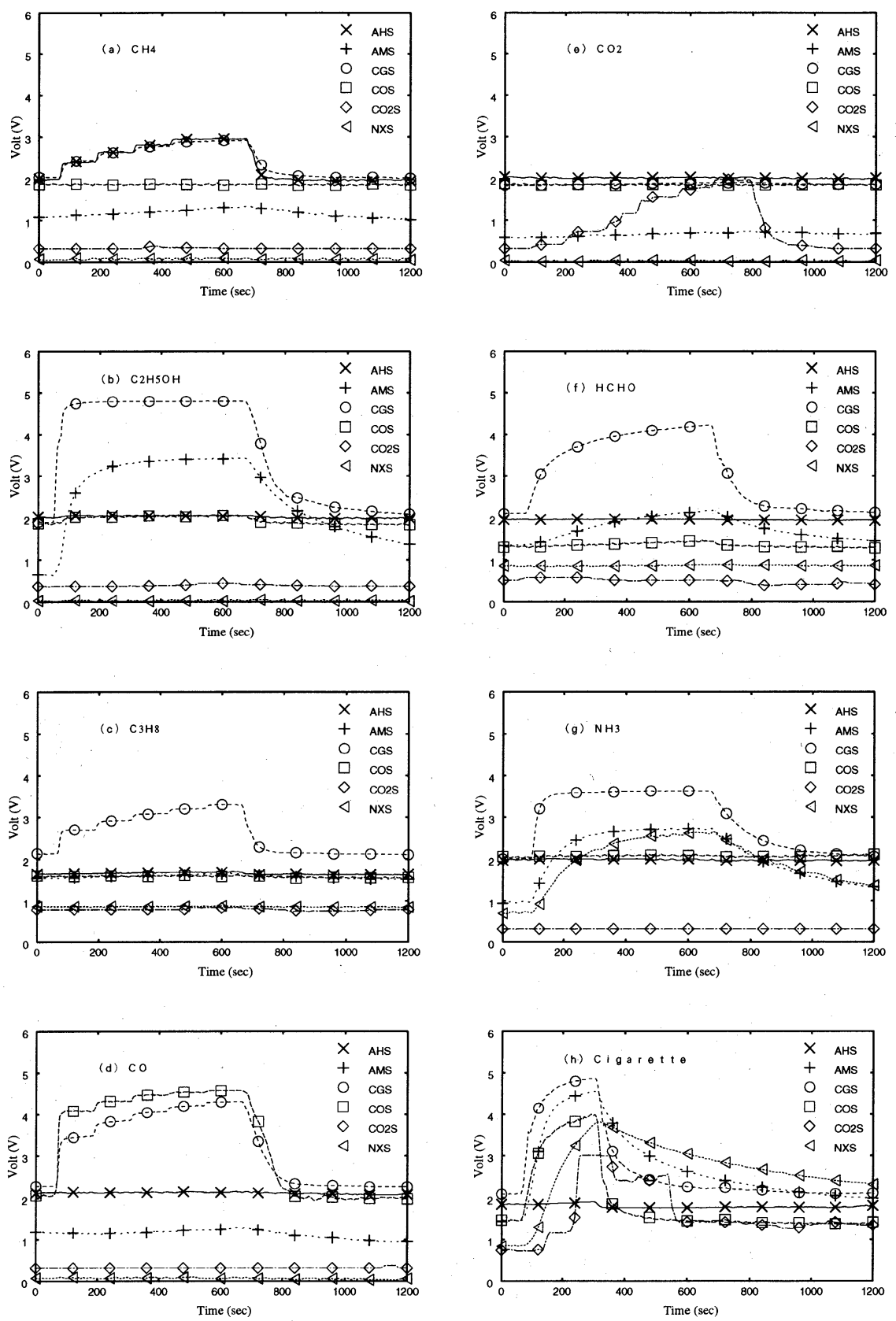

Fig. 6 The observation signal by six gas sensors.

別々に実験開始から 60 秒後に注入し， 660 秒後に容器を開 放して定常時大気に戻した. 前述した判定ルールを作るた め, ガス注入時の各センサ反応範囲を調べ, 式 (1) の入力 值を比較するための知識べクトル領域を選定した. ガス濃 度の最大值は約 $20000 \mathrm{ppm}$ である.このときの電圧 $V_{\max }$ をセンサ反応範囲の最大值とした。 最小電圧 $V_{\min }$ は測定前 の定常電圧程度に設定した. Fig. 5 にガス注入時の各セン サ反応範囲を示す. Fig. 5（a）〜（h）はそれぞれ，メタン, エタノール, プロパン, 一酸化炭素, 二酸化炭素, ホルム アルデヒド, アンモニア, タバコの煙に対する各ガスセン サ出力電圧の有効範囲 $\left(V_{\min } \sim V_{\max }\right)$ である. また, 濃度 指標を求める簡略式 $(2)$ を求めるため, $V_{k}$ 軸が太線で指示
してある. Fig. 5（a）～（h）の濃度指標算出軸はそれぞれ， AHS, CGS, CGS, COS, CO2S, CGS, AMS, AMS で ある. Fig. 5 からもわかるように, 本実験で選定した 8 つの ガス種の知識ベクトル領域（単一ガス 7 種, 複合ガス 1 種) において, 低電圧域で僅かな重なり部分が確認されたが, 各 ガス種同士の重なり領域は少なく, ほぼ知識領域が独立して いる. 本システムでは, 低濃度域で複数のガスが検知されて も, 式 (2) の濃度指標値を用いているためシステム出力値 から, 低濃度域での誤差か, 未知のガス種によるものなのか 判定できる. Fig. 2 のガス種判定知識として, Fig. 5 に示さ れる 8 つ図を判定ルールとして知識ベース化した (付録). 
(\%)

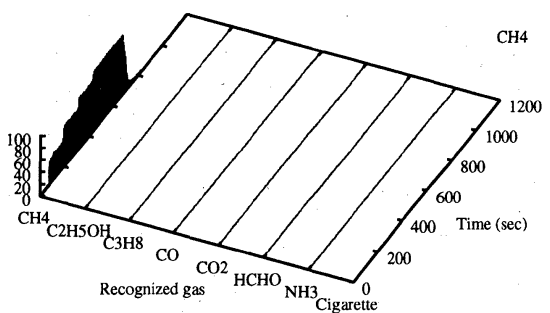

(a) $\mathrm{CH} 4$

(\%)

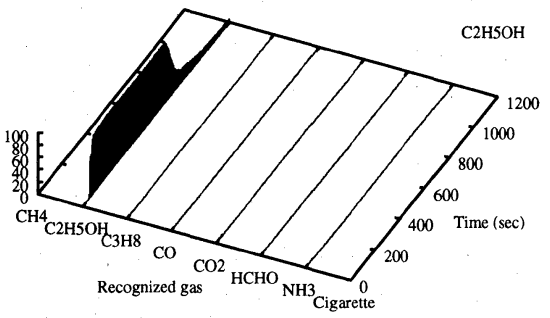

(b) $\mathrm{C} 2 \mathrm{H} 5 \mathrm{OH}$

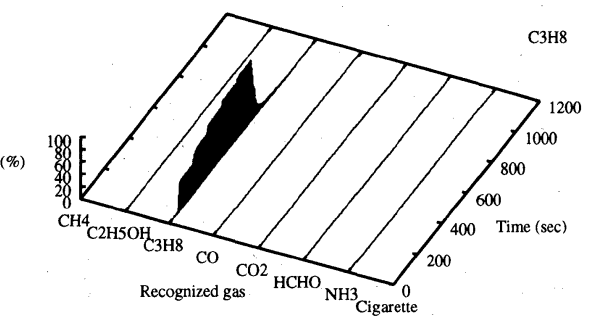

(c) $\mathrm{C} 3 \mathrm{H} 8$

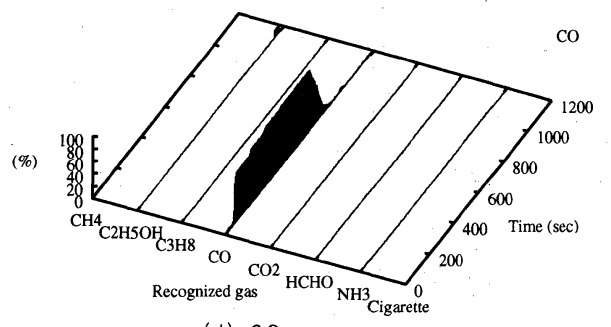

(d) $\mathrm{CO}$
(\%)

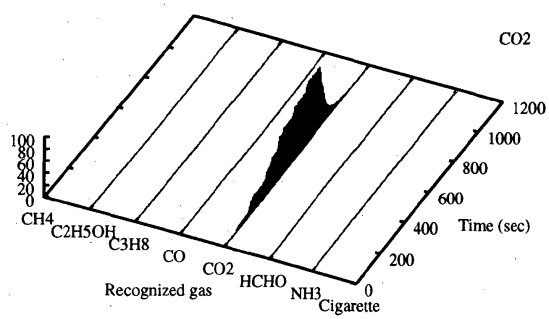

(e) $\mathrm{CO}_{2}$

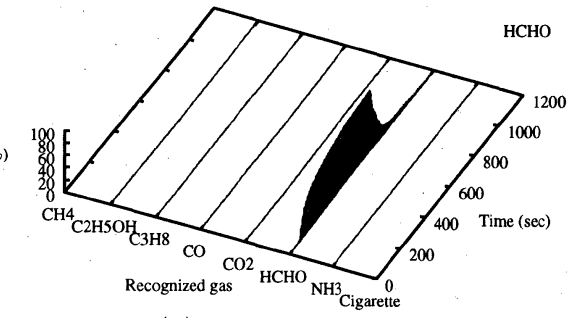

(f) $\mathrm{HCHO}$

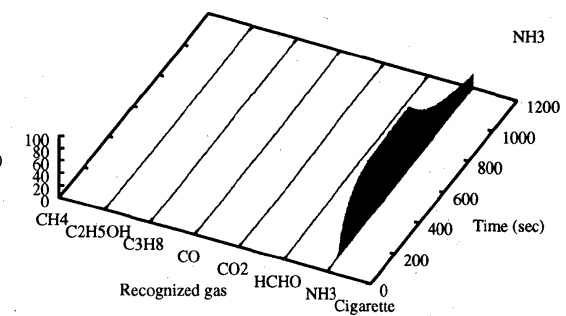

(g) $\mathrm{NH}_{3}$

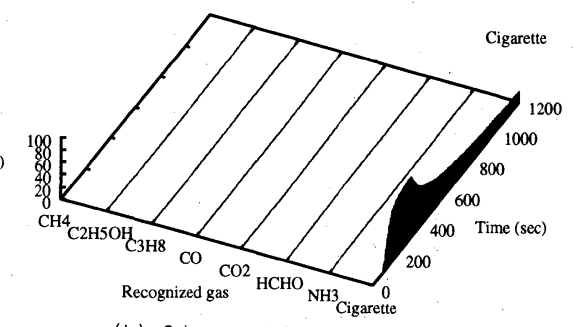

(h) Cigarette

Fig. 7 The output signal determined by the knowledge base.

\section{5. 判 定実 験}

Fig. 6 でガス種の各ガスセンサに反応した観測信号を示 す. Fig. 6 (a) はメタンを周期的に 120 秒間注入し, 飽和状 態（180 秒間）をえて, 換気したときの各センサ観測信号で ある.それぞれ図中の×は AHS，+は AMS，。は CGS，口

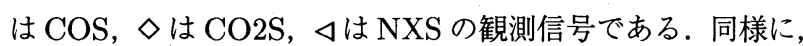
Fig.6（b）〜（h）はそれぞれ，エタノール，プロパン，一 酸化炭素, 二酸化炭素, ホルムアルデヒド, アンモニア, 夕 バコの煙を注入したときのセンサ観測信号である.

Fig. 6 をそれぞれ Fig. 2 に示される入力として用い, 判定 実験を行った. Fig. 7 は Fig. 2 のシステムによって判定され た出力信号である．高さは式（2）によって求められた簡略 的な濃度指標值である. Fig. 7 (a) はFig. 6 (a) に示される メタン注入時の観測信号をシステム入力信号としたときの判
定結果である. 同様に, Fig.7（b）～（h）はそれぞれ Fig.6 (b) 〜（h）を入力信号として与えたときの判定結果である. Fig. 7 (d) の時間後半（約 1130 秒目）で, 定常時に近い低 濃度域のため, 一酸化炭素をエ夕ノールと判定してしまうが, おおむね，ガス種を正確に判断していることがわかる. Fig. 6 に示される範囲において，ガス注入時から開放までの時間区 間では認知率が平均 $100 \%$ ，それ以外の区間では平均 $98 \%$, 全区間では平均 $99 \%$ と高い認知率が得られた。

\section{6. をと}

室内環境污染度を定量的に計測するため，6つのガスセン サから各出力信号を観測し，単一ガス（7 種）, 複合ガス（1 種）計 8 種類の認知実験を試みた。本論文では，ガス種ごと に独立した認知ルールを設けた。 反応媒質に対し6つのセン サ出力値をベクトル化し，6次元ベクトル空間でガスごとに 
判定領域を定め入力信号に対しガス種の認知と簡易的な濃度 指標值を算出した。 その結果, 6 次元ベクトル空間上では 8 つの判定領域はほほ独立して存在することがわかった。また, 判定実験では定常出力に近い低濃度域でわずかな判定ミスが 確認されるものの, 濃度指標值から判定ミスを補える情報が 得られることがわかった．濃度補正を与えない認知率は 99 \%であり，濃度補正を考慮するとほほ $100 \%$ の認知率が得ら れる可能性を示した。

\section{参 考 文 献}

1）瀬沼 勲：“室内環境学”, 三共出版 (1990)

2) T.Oyabu, H.Kimura, Y.Kajiyama, M.Honda, S.Ishizuka: "Estimation System for Domestic disaster using production system", 183rd Meeting of the Electro - chemical Society,Honolulu, Hawaii, USA, pp.589-596, (1993)

3）大藪, 木村:“プロダクションシステムを用いた家庭内災害認知”, 計測自動制御学会論文集，Vol.30， No.9， pp.1077-1083 (1994）. .

4) T.Oyabu, H.Kimura:"Indoor Air-Pollution Detector Using Tin-Oxide Gas Sensor", Sensors and Materials, Vol.7, No.6, pp.431-436 (1995)

5）大薮, 木村：” 新しい室内空気污染検知システムの開発”, 計 測自動制御学会論文集, Vol.32, No.7, pp.1121-1128(1996)

6）大薮，木村：”プロダクションシステムを用いた相対的室内空 気污染の測定”, 電学論 E, Vol.117, No.5, pp.243-249 (1997)

7）大藪, 蔡, 石坂, 木村, 松浦, 梶山： “マルチセンサの室内空 気污染物に対する出力特性”, Digest of the 20th Chemical Sensor Symposium (電気化学協会·化学センサ研究会) Vol.11 Supplement A, No.11, pp.49-52（1995 年 4 月）

8) L.Brownston, R.Farrell, E.Kant and N.Martin: "Programming Expert System in OPS5:Introduction to Rule-Based Programming", Addison Wesley, (1985)

9) W.Göpel et al., "Sensors, Vol.2 Chemical and Biochemical Sensors, Part I", VCH Publishers Inc., New York, NY, pp.191-237, (1991)

\section{《付 録》}

; ; マルチセンサの測定值を表すWME

(literalize value ; クラス名

num ;; 時系列

ahs $\quad ;$; AHS $の$ 值

ams $\quad ;$; AMS $の$ 值

cgs ; ; CGS の值

$\cos \quad ; ; \cos の$ 值

$\operatorname{co} 2 \mathrm{~s} ;$; $\operatorname{CO2S}$ の值

$\mathrm{nxs}) \quad ;$; NXS の值

; ; 各センサ出力值の上限と下限を表すWME

(literalize ch4d ;; CH4 が存在する場合

ahsl ; ; AHS の電圧の下限

ahsu ;; AHS の電圧の上限

amsl ；； AMS の電圧の下限

amsu ; ; AMS の電圧の上限

cgs1 ; ; CGS の電圧の下限

cgsu ; ; CGS の電圧の上限

$\cos 1 \quad ; ; \cos$ の電圧の下限

$\operatorname{cosu} \quad ; ; \cos$ の電圧の上限

co2s1 ; ; CO2S の電圧の下限

$\mathrm{co} 2 \mathrm{su} ; ; \mathrm{CO} 2 \mathrm{~S}$ の電圧の上限

$\mathrm{nxs1} \quad$; $; \mathrm{NXS}$ の電圧の下限

$\mathrm{nxsu}) ; ; \mathrm{NXS}$ の電压の上限

(literalize ethd ; ; C $2 \mathrm{H} 5 \mathrm{OH}$ が存在する場合

ahsl ahsu amsl amsu cgsl cgsu

$\cos l \operatorname{cosu} \operatorname{co} 2 s l$ co2su nxsl nxsu)

(literalize prod ; ; C 3 H8 が存在する場合 ahsl ahsu amsl amsu cgsl cgsu $\cos 1$ cosu co2sl co2su nxsl nxsu)

(literalize cod ;; COが存在する場合

ahsl ahsu amsl amsu cgsl cgsu $\cos 1$ cosu co2sl co2su nxsl nxsu)

(literalize co2d ; ; CO2 が存在する場合

ahsl ahsu amsl amsu cgsl cgsu

$\cos 1$ cosu co2sl co2su nxsl nxsu)

(literalize fsd ; ; HCHOが存在する場合

ahsl ahsu amsl amsu cgsl cgsu

$\cos 1$ cosu co2sl co2su nxsl nxsu)

(literalize nh3d ; N N 3 が存在する場合

ahsl ahsu amsl amsu cgsl cgsu

$\cos 1$ cosu co2sl co2su nxsl nxsu)

(literalize cigd ; ; タバコの煙が存在する場合

ahsl ahsu amsl amsu cgsl cgsu

$\cos 1$ cosu co2sl co2su nxsl nxsu)

(literalize time ; ; 各ガスを感知したかどうかを知るWME

num ; ; 時系列

ch4 ; ; $\mathrm{CH} 4$

eth ;; $\mathrm{C} 2 \mathrm{H} 5 \mathrm{OH}$

pro ; ; $\mathrm{C} 3 \mathrm{H} 8$

co ; ; $\mathrm{CO}$

$\mathrm{CO} 2 ; ; \mathrm{CO} 2$

fs ; ; $\mathrm{HCHO}$

nh3 ;; $\mathrm{NH} 3$

cig) ; ; タバコの煙

(literalize init

setup)

（p startup ; ; 初期データを入力する startup 文

(init "setup start)

$-->$

(make ch4d -ahsl 1937 -ahsu 2966 aamsl 1005

‘amsu 1321 “cgsl 1999 "cgsu 2920

${ }^{-} \cos 11822{ }^{\circ} \operatorname{cosu} 1892{ }^{\circ} \cos \mathrm{s} 1310$

-co2su 375 "nxsl 45 ^nxsu 100)

(make ethd -ahsl 1972 -ahsu 2073 -amsl 636

-amsu 3430 -cgsl 1895 "cgsu 4805

${ }^{-} \cos 11821-\operatorname{cosu} 2071{ }^{-\operatorname{co} 2 s l} 362$

‘co2su 450 ^nxsl 5 'nxsu 55)

(make prod "ahsl 1619 "ahsu 1700 "amsl 1507

-amsu 1656 -cgs1 2100 "cgsu 3307

${ }^{-} \cos 11534{ }^{-} \operatorname{cosu} 1619{ }^{\circ} \operatorname{co} 2 s 1737$

-co2su 835 -nxsl 835 'nxsu 873)

(make cod ^ahsl 2065 -ahsu 2157 -amsl 949

-amsu 1294 'cgsl 2267 'cgsu 4313

- $\cos 11932$ - $\operatorname{cosu} 4581{ }^{-} \operatorname{co2s} 1311$

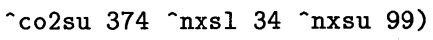

(make co2d -ahsl 1979 -ahsu 2039 -amsl 570

-amsu 736 "cgsl 1825 "cgsu 1908

${ }^{-} \cos 118200^{-} \operatorname{cosu} 1883{ }^{-} \cos \mathrm{sl} 311$

-co2su 2000 'nxsl 3 'nxsu 45)

(make fsd -ahsl 1931 -ahsu 1970 -amsl 1347

-amsu 2179 "cgsl 2100 "cgsu 4232

- cosl 1283 - cosu $1463-\operatorname{co2sl} 391$

'co2su 582 "nxsl 834 'nxsu 888)

(make nh3d -ahsl 1946 ^ahsu 2007 `amsl 933

-amsu 2734 'cgsl 1994 -cgsu 3633

${ }^{\wedge} \cos 12017{ }^{\circ} \operatorname{cosu} 2121{ }^{\circ} \operatorname{co} 2 \mathrm{sl} 310$

-co2su 315 nxsl 682 nxsu 2654)

(make cigd "ahsl 1752 "ahsu 1905 "amsl 1438

-amsu 4555 -cgsl 2085 -cgsu 4869

${ }^{-} \cos 11365{ }^{\prime} \operatorname{cosu} 4008{ }^{\circ} \operatorname{coss} 1726$

- co2su 3020 -nxsl 833 inxsu 3822)

(make time -num -1 " ch4 no "eth no "pro no

-co no " $\operatorname{co} 2$ no ${ }^{-}$s $\mathrm{s}$ no "nh3 no - cig no))

（p r0 ; ; マルチセンサの最初の測定値を出すルール r0 
(time -num -1 - $\operatorname{ch} 4$ no -eth no $p r o$ no -co no " $\operatorname{co} 2$ no 'fs no -nh3 no -cig no)

$\rightarrow$

(modify 1 num 0 ))

（p r1 ; ; C $\mathrm{CH} 4$ を検出するルール r1

(time -num $\langle\mathrm{n}\rangle$ " ch4 no)

(value "num $\langle n\rangle$ "ahs $\langle a\rangle$ "ams $\langle b\rangle$ "cgs $\langle c\rangle$ $\left.{ }^{-} \cos \langle d\rangle-\operatorname{co} 2 \mathrm{~s}\langle\mathrm{e}\rangle{ }^{-n} \mathrm{nxs}\langle\mathrm{f}\rangle\right)$

(ch4d ahs $\{\langle p\rangle\langle=\langle a\rangle\}$ ahsu $\{\langle q\rangle\rangle=\langle a\rangle\}$ -amsl $\langle=\langle\mathrm{b}\rangle$ "amsu $\rangle=\langle\mathrm{b}\rangle{ }^{-c} \operatorname{cgsl}\langle=\langle\mathrm{c}\rangle$ "cgsu $\rangle=\langle\mathrm{c}\rangle{ }^{-} \cos 1\left\langle=\langle\mathrm{d}\rangle \cdot{ }^{-} \operatorname{cosu}\right\rangle=\langle\mathrm{d}\rangle$ ${ }^{-} \operatorname{co} 2 \mathrm{~s} l\left\langle=\langle\mathrm{e}\rangle{ }^{-}{ }^{-} \mathrm{co} 2 \mathrm{su}\right\rangle=\langle\mathrm{e}\rangle{ }^{n} \mathrm{nxsl}\langle=\langle\mathrm{f}\rangle$ nxsu $\rangle=\langle f\rangle$ )

$$
\rightarrow
$$

(write (crlf) <n> "I detected CH4.")

(modify 1 "ch4 yes)

(bind 〈perahs>

(compute $((\langle a\rangle-\langle p\rangle) * 100) / /(\langle q\rangle-\langle p\rangle)))$ (write 〈perahs $>)$ )

(p r2 ; ; C 2 H 5 OHを検出するルール r2

(time "num $\langle n\rangle$ "eth no)

(value "num $\langle\mathrm{n}\rangle$-ahs $\langle\mathrm{a}\rangle$-ams $\langle\mathrm{b}\rangle$-cgs $\langle\mathrm{c}\rangle$ ${ }^{-} \cos \langle\mathrm{d}\rangle{ }^{-} \operatorname{co} 2 \mathrm{~s}\langle\mathrm{e}\rangle-\mathrm{nxs}\langle\mathrm{f}\rangle$

(ethd "ahsl $\langle=\langle a\rangle$-ahsu $\rangle=\langle a\rangle$ - amsl $\langle=\langle b\rangle$

-amsu $\rangle=\langle\mathrm{b}\rangle{ }^{-c g s} 1\{\langle\mathrm{p}\rangle\langle=\langle\mathrm{c}\rangle\}$

-cgsu $\{\langle\mathrm{q}\rangle\rangle=\langle\mathrm{c}\rangle\}-\cos 1\langle=\langle\mathrm{d}\rangle$

$\left.{ }^{-} \operatorname{cosu}\right\rangle=\langle\mathrm{d}\rangle{ }^{\circ} \operatorname{co} 2 \mathrm{~s} 1\left\langle=\langle\mathrm{e}\rangle{ }^{\prime} \operatorname{co} 2 \mathrm{su}\right\rangle=\langle\mathrm{e}\rangle$

${ }^{n} \mathrm{nxsl}\left\langle=\langle\mathrm{f}\rangle{ }^{n} \mathrm{nxsu}\right\rangle=\langle\mathrm{f}\rangle$ )

$-->$

(write (crlf) 〈n〉 "I detected C2H5OH.")

(modify 1 "eth yes)

(bind <percgs>

$($ compute $((\langle c\rangle-\langle p\rangle) * 100) / /(\langle q\rangle-\langle p\rangle)))$ (write <percgs $>$ )

（p r3 ; ; C 3 H 8 を検出するルール r3

(time "num 〈n〉 "pro no)

(value 'num $\langle\mathrm{n}\rangle$-ahs $\langle\mathrm{a}\rangle$-ams $\langle\mathrm{b}\rangle{ }^{-} \mathrm{cgs}\langle\mathrm{c}\rangle$ $\left.{ }^{-} \cos \langle\mathrm{d}\rangle{ }^{-} \operatorname{co} 2 \mathrm{~s}\langle\mathrm{e}\rangle{ }^{-n x s}\langle\mathrm{f}\rangle\right)$

(prod -ahsl $\langle=\langle a\rangle$-ahsu $\rangle=\langle a\rangle-a m s l\langle=\langle b\rangle$ -amsu $\rangle=\langle\mathrm{b}\rangle{ }^{-} \operatorname{cgsl}\{\langle\mathrm{p}\rangle\langle=\langle\mathrm{c}\rangle\}$

$\left.{ }^{-} \operatorname{cgsu}\{\langle q\rangle\rangle=\langle\mathrm{c}\rangle\right\}{ }^{-} \cos 1\langle=\langle\mathrm{d}\rangle$

$\left.{ }^{-} \operatorname{cosu}\right\rangle=\langle\mathrm{d}\rangle{ }^{\circ} \operatorname{co} 2 \mathrm{~s} 1\left\langle=\langle\mathrm{e}\rangle{ }^{\circ} \operatorname{co} 2 \mathrm{su}\right\rangle=\langle\mathrm{e}\rangle$

${ }^{\circ} \mathrm{nxsl}\left\langle=\langle\mathrm{f}\rangle{ }^{-n x s u}\right\rangle=\langle f\rangle$ )

$-\rightarrow$

(write (crlf) $\langle n>$ "I detected Propane.")

(modify 1 "pro yes)

(bind 〈percgs>

$$
\text { (compute }((\langle c\rangle-\langle p\rangle) * 100) / /(\langle q\rangle-\langle p\rangle)))
$$

(write 〈percgs $>$ ))

（p r4 ; ; CO 検出するルール r4

(time "num $\langle n\rangle$ " co no)

(value -num $\langle n\rangle$-ahs $\langle a\rangle$-ams $\langle\mathrm{b}\rangle$ " $\mathrm{cgs}\langle\mathrm{c}\rangle$ $\left.{ }^{\prime} \cos \langle\mathrm{d}\rangle{ }^{-} \operatorname{co} 2 \mathrm{~s}\langle\mathrm{e}\rangle{ }^{-} \mathrm{nxs}\langle\mathrm{f}\rangle\right)$

(cod "ahsl $\langle=\langle a\rangle$ "ahsu $\rangle=\langle a\rangle$ "amsl $\langle=\langle b\rangle$

-amsu $\rangle=\langle b\rangle$ " cgsl $\langle=\langle\mathrm{c}\rangle$ " cgsu $\rangle=\langle\mathrm{c}\rangle$

${ }^{\prime} \cos 1\left\{\langle p\rangle\langle=\langle d\rangle\}{ }^{\prime} \operatorname{cosu}\{\langle q\rangle\rangle=\langle d\rangle\right\}$

${ }^{\prime} \operatorname{co} 2 \mathrm{~s} 1\left\langle=\langle\mathrm{e}\rangle{ }^{\prime}{ }^{\mathrm{c}} \mathrm{co} 2 \mathrm{su}\right\rangle=\langle\mathrm{e}\rangle{ }^{\circ} \mathrm{nxsl}\langle=\langle\mathrm{f}\rangle$

"nxsu $\rangle=\langle f\rangle$ )

$-->$

(write (crlf) 〈n> "I detected Co.")

(modify 1 "co yes)

(bind 〈percos>

$($ compute $((\langle\mathrm{d}\rangle-\langle\mathrm{p}\rangle) * 100) / /(\langle\mathrm{q}\rangle-\langle\mathrm{p}\rangle)))$

(write $\langle$ percos $>)$ ) （p r5 ；；ＣＯ2 を検出するルール r5

(time "num 〈n〉 " co2 no)

(value -num $\langle n\rangle$-ahs $\langle a\rangle$-ams $\langle\mathrm{b}\rangle{ }^{-}$cgs $\langle\mathrm{c}\rangle$ $\left.{ }^{-} \cos \langle d\rangle{ }^{\circ} \operatorname{co} 2 s\langle e\rangle{ }^{n} n x s\langle f\rangle\right)$

$(\operatorname{co} 2 \mathrm{~d}$-ahsl $\langle=\langle\mathrm{a}\rangle$ "ahsu $\rangle=\langle\mathrm{a}\rangle$-amsl $\langle=\langle\mathrm{b}\rangle$ 'amsu $\rangle=\langle b\rangle$ " cgsl $\langle=\langle c\rangle$ " cgsu $\rangle=\langle c\rangle$ ${ }^{-} \cos 1\left\langle=\langle\mathrm{d}\rangle{ }^{-} \operatorname{cosu}\right\rangle=\langle\mathrm{d}\rangle$

${ }^{-} \cos s 1\{\langle\mathrm{p}\rangle\langle=\langle\mathrm{e}\rangle\}$ " $\operatorname{co} 2 \mathrm{su}\{\langle\mathrm{q}\rangle\rangle=\langle\mathrm{e}\rangle\}$

"nxsl $\langle=\langle f\rangle \cdot n x s u\rangle=\langle f\rangle$ )

$-->$

(write (crlf) <n> "I detected C02.")

(modify 1 "co2 yes)

(bind 〈perco2s>

$($ compute $((\langle\mathrm{e}\rangle-\langle\mathrm{p}\rangle) * 100) / /(\langle\mathrm{q}\rangle-\langle\mathrm{p}\rangle)))$ (write $\langle$ perco2s $>$ )

（p r6 ; ; HCHOを検出するルール r6

(time "num 〈n〉 'fs no)

(value "num $\langle n\rangle$ "ahs $\langle a\rangle$ "ams $\langle\mathrm{b}\rangle$ " cgs $\langle c\rangle$ $\left.{ }^{-} \cos \langle\mathrm{d}\rangle{ }^{-} \operatorname{co} 2 \mathrm{~s}\langle\mathrm{e}\rangle{ }^{-n x s}\langle\mathrm{f}\rangle\right)$

(fsd "ahsl $\langle=\langle a\rangle$ "ahsu $\rangle=\langle a\rangle$ "amsl $\langle=\langle\mathrm{b}\rangle$

-amsu $\rangle=\langle\mathrm{b}\rangle \cdot \operatorname{cgsl}\{\langle\mathrm{p}\rangle\langle=\langle\mathrm{c}\rangle\}$

- $\operatorname{cgsu}\{\langle q\rangle\rangle=\langle c\rangle\}-\cos 1\langle=\langle\mathrm{d}\rangle$

$\left.{ }^{-} \operatorname{cosu}\right\rangle=\langle\mathrm{d}\rangle \cdot \operatorname{co} 2 \mathrm{~s} 1\langle=\langle\mathrm{e}\rangle \cdot \operatorname{co} 2 \mathrm{su}\rangle=\langle\mathrm{e}\rangle$

$\rightarrow$

$\left.{ }^{\prime} n x s l\left\langle=\langle f\rangle{ }^{-n x s u}\right\rangle=\langle f\rangle\right)$

(write (crlf) <n> "I detected нСно.")

(modify 1 -fs yes)

(bind 〈percgs>

$($ compute $((\langle c\rangle-\langle p\rangle) * 100) / /(\langle q\rangle-\langle p\rangle)))$

(write 〈percgs〉))

（p r7 ; ; N H 3 を検出するルール r7

(time "num $\langle\mathrm{n}\rangle{ }^{-}$nh3 no)

(value 'num $\langle\mathrm{n}\rangle$ - ahs $\langle\mathrm{a}\rangle$ "ams $\langle\mathrm{b}\rangle$ " $\mathrm{cgs}\langle\mathrm{c}\rangle$ $\left.{ }^{-} \cos \langle d\rangle{ }^{-} \operatorname{co} 2 s\langle e\rangle{ }^{n} n x s\langle f\rangle\right)$

(nh3d -ahsl $\langle=\langle\mathrm{a}\rangle$-ahsu $\rangle=\langle\mathrm{a}\rangle$-amsl $\{\langle\mathrm{p}\rangle\langle=\langle\mathrm{b}\rangle\}$ -amsu $\{\langle q\rangle\rangle=\langle b\rangle\}$ " cgsl $\langle=\langle c\rangle$ - cgsu $\rangle=\langle c\rangle$

${ }^{-} \cos 1\left\langle=\langle\mathrm{d}\rangle{ }^{-} \operatorname{cosu}\right\rangle=\langle\mathrm{d}\rangle{ }^{-} \operatorname{co} 2 \mathrm{sl}\langle=\langle\mathrm{e}\rangle$

$\left.\left.{ }^{-} \mathrm{co} 2 \mathrm{su}\right\rangle=\langle\mathrm{e}\rangle{ }^{\prime} \mathrm{nxsl}\left\langle=\langle\mathrm{f}\rangle{ }^{\prime} \mathrm{nxsu}\right\rangle=\langle\mathrm{f}\rangle\right)$

$-->$

(write (crlf) <n> "I detected NH3.")

(modify 1 "nh3 yes)

(bind <perams>

(compute $((\langle\mathrm{b}\rangle-\langle\mathrm{p}\rangle) * 100) / /(\langle\mathrm{q}\rangle-\langle\mathrm{p}\rangle)))$

(write <perams $>)$ )

（p r8 ; ; タバコの煙を検出するルール r8

(time "num 〈n〉 " cig no)

(value "num $\langle n\rangle$ "ahs $\langle a\rangle$ "ams $\langle\mathrm{b}\rangle{ }^{\circ} \mathrm{cgs}\langle\mathrm{c}\rangle$ $\left.{ }^{-} \cos \langle\mathrm{d}\rangle{ }^{\prime} \operatorname{co} 2 \mathrm{~s}\langle\mathrm{e}\rangle{ }^{-n} \mathrm{nxs}\langle\mathrm{f}\rangle\right)$

(cigd "ahsl $\langle=\langle a\rangle$ "ahsu $\rangle=\langle a\rangle$ "amsl $\{\langle p\rangle\langle=\langle b\rangle\}$ -amsu $\{\langle\mathrm{q}\rangle\rangle=\langle\mathrm{b}\rangle\}{ }^{\circ}$ cgsl $\langle=\langle\mathrm{c}\rangle$ " cgsu $\rangle=\langle\mathrm{c}\rangle$ ${ }^{-} \cos 1\left\langle=\langle\mathrm{d}\rangle{ }^{-} \operatorname{cosu}\right\rangle=\langle\mathrm{d}\rangle{ }^{-} \operatorname{co} 2 \mathrm{~s} 1\langle=\langle\mathrm{e}\rangle$

$\left.{ }^{-} \mathrm{co} 2 \mathrm{su}\right\rangle=\langle\mathrm{e}\rangle{ }^{-} \mathrm{nxs} 1\left\langle=\langle\mathrm{f}\rangle{ }^{-n} \mathrm{nxsu}\right\rangle=\langle\mathrm{f}\rangle$ )

$-->$

(write (crlf) $\langle n>$ "I detected Cigarette.")

(modify 1 -cig yes)

(bind <perams>

(compute $((\langle b\rangle-\langle p\rangle) * 100) / /(\langle q\rangle-\langle p\rangle)))$

(write <perams $>)$ )

（p r9 ; ; 反応がないときにつぎの測定值を出すルール r9

(time "num $\langle n\rangle$ "ch4 no "eth no "pro no "co no "co2 no "fs no "nh3 no "cig no)

(value "num $\langle n\rangle$-ahs $\langle a\rangle$-ams $\langle b\rangle$ - $c g s\langle c\rangle$ $\left.{ }^{-} \cos \langle\mathrm{d}\rangle{ }^{-} \operatorname{co} 2 \mathrm{~s}\langle\mathrm{e}\rangle{ }^{-n} \mathrm{nxs}\langle\mathrm{f}\rangle\right)$

$-->$

(write (crlf) <n> "I didn't know." (crlf)) 


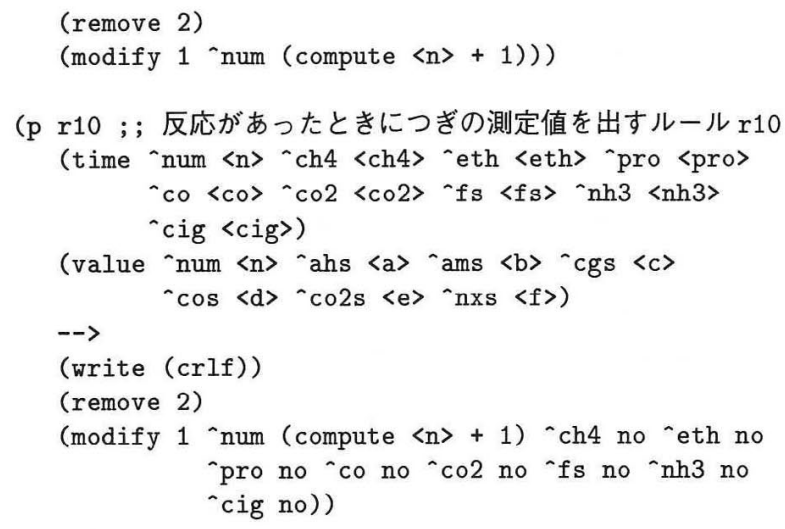

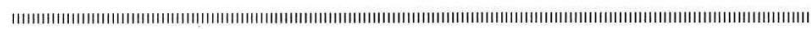

\section{[著 者 紹 介]}

\section{広 林 茂 樹（正会員）}

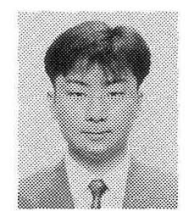

1968 年 9 月 1 日生まれ. 94 年 3 月工学院大学 工学研究科修士課程修了. 95 年 3 月同大学博士課 程中退. 同年 4 月金沢大学工学部助手. 主として, 室内音響, 音響振動論, 音響信号処理, 流体伝播 のモデル化の研究に従事. 電子情報通信学会, 電 気学会, 日本音響学会, 米国音響学会各会員.

\section{木 村 春 彦}

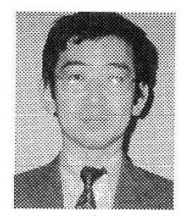

1974 年, 東京電機大学工学部応用理化学科卒 業. 79 年東北大学工学研究科博士 (情報工学) 課 程修了. 同年富士通 (株) 勤務. 80 年金沢女子短 期大学講師. 84 年金沢大学経済学部助教授を経 $\tau$, 現在, 同大学工学部電気・情報工学科教授. そ の間, 最適コード変換, プロダクションシステム の高速化の研究に従事 (工学博士).

\section{南 保 英 孝}

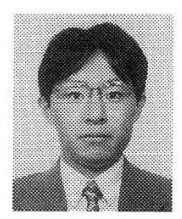

1994 年金沢大学工学部電気・情報工学科卒業. 96 年同大学院電気. 情報工学専攻修士課程終了. 同年, 同大学院自然科学研究科システム科学専攻 博士課程進学. 現在に至る. その間, プロダクショ ンシステムに関する研究, 特に, 高コストルール 対処法, 高速条件照合アルゴリズムに関する研究 に従事. 電子情報通信学会会員.

\section{坂 森智}

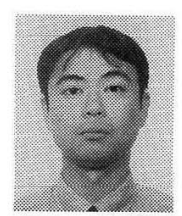

1975 年 8 月 25 日生まれ。 98 年 3 月金沢大学工 学部電気情報工学科卒業. 98 年 4 月より同大学院 博士前期課程在学中. ガスセンサを用いた人の活 動同定に興味がある．電気学会会員.

\section{大 薮 多可志 (正会員)}

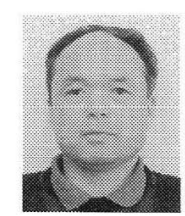

1973 年, 工学院大学工学研究科修士過程終了. 75 年早稲田大学第二文学部英文学科卒業. 73 年 電気音響（株）技術研究所勤務. 80 年金沢女子 短期大学講師, 助教授, 教授, 91 年富山国際大学 人文学部社会学科助教授, 教授. 98 年金沢経済大 学教授. ガスセンサシステムに関する研究に従事 (工学博士)

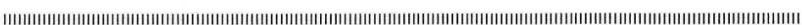

